\title{
Harnessing New Media Tools in Patient Information
}

\author{
Thorsten Bach $^{a, *}$, Mark Behrendt ${ }^{b}$, Yiloren Tanidir ${ }^{c}$, Philip Cornford ${ }^{d}$, Yinghao Sun ${ }^{e}$, \\ Hendrik Van Poppel ${ }^{f}$
}

${ }^{a}$ Urology Department, Asklepios Hospital Harburg, Hamburg, Germany; ${ }^{\mathrm{b}}$ The Netherlands Cancer Institute, Antoni van Leeuwenhoek Hospital, Amsterdam, The Netherlands; ' Marmara University, Urology Istanbul, Turkey; ${ }^{\mathrm{d}}$ Urology Department, Royal Liverpool and Broadgreen University Hospitals NHS Trust, Liverpool, UK; ${ }^{\mathrm{e}}$ Urology Department, Shanghai Second Military Medical University Hospital, Shanghai, People's Republic of China; ${ }^{\mathrm{f}}$ Urology Department, UZ Leuven, Leuven, Belgium

In this age of information technology, new media tools and their adoption by patients have both benefits and drawbacks. Contemporary patient information platforms have come a long way from their print-based origins to the more sophisticated one-click, website-anchored programs published by health and medical organisations. In previous decades patients were mainly dependent on health care experts for vital information on health conditions and their therapies. Today, a plethora of information sources pose a challenge to health care professionals, with patients struggling to understand and appropriately apply specialised information. Often, physicians have to help patients in navigating through conflicting and overly optimistic marketing sites to allow them to understand their disease and the options open to them.

The European Association of Urology Patient Information (EAU PI) is part of this trend in digital communication, delivering specialised information and high-quality content that is readily accessible, trustworthy, and understandable by the general public. The aims are to provide accurate information and facilitate communication between doctors and patients. The EAU PI benefits from the support and the work of the EAU guidelines, considered as one of the most comprehensive guidelines worldwide, and therefore has the distinction of being evidence-based.

Besides written text, the EAU PI includes animated videos to educate patients (Fig. 1). A pilot study [1] was recently conducted to assess the level of understanding among patients who were scheduled for ureteroscopy. An animated video and written information about the procedure were shown to patients before any contact with hospital staff. Tanidir et al [1] developed an 11-item questionnaire to evaluate patients' ratings, followed by two questions testing their level of understanding of the information provided (Fig. 2A). For this study, the information source and the questionnaire were translated into German, Turkish, and Chinese for multilingual evaluation.

A total of 162 questionnaires were evaluated (52 in Germany, 61 in Turkey, and 49 in China). Of the participants, $58 \%$ were male and $42 \%$ were female, while $33 \%$ were aged 19-39 yr, $46 \%$ were $40-59 \mathrm{yr}$, and $21 \%$ were $>59 \mathrm{yr}$. Satisfaction with the information presented was very high: $90 \%$ of the comments received were favourable, with $<2 \%$ of patients disappointed with the educational material provided. Most impressively, $99 \%$ of the patients considered the information useful in preparing for the procedure. There were no significant differences in evaluation of the items between nationalities, except for the need for voiceover and subtitles, with $92.2 \%$ of Chinese patients preferring this option, as compared to voiceover only preferred in Turkey (67.8\%) and Germany (73.5\%).

The authors concluded that the EAU PI provides carefully written educational material with the aid of a video showing how a procedure is performed. They noted that "It raises the level of understanding and improves patient confidence prior to treatment in $97.5 \%$ of participants. The pilot study also indicated that a small number of patients do not understand the information delivered to them, suggesting the need for detailed evaluation of possible weak points in order to further enhance PI material."

In their 2015 study, Meppelink et al [2] obtained similar results, confirming. “... spoken animation is the best way to communicate complex health information to people with low health literacy." They also noted that since animations

* Corresponding author. Urology Department, Asklepios Hospital Harburg, Eissendorfer Pferdeweg 52, Hamburg 21075, Germany. Tel. +49 401818862555 ; Fax: +49 401818762555 .

https://doi.org/10.1016/j.eururo.2018.09.018

0302-2838/C 2018 European Association of Urology. Published by Elsevier B.V. All rights reserved. 


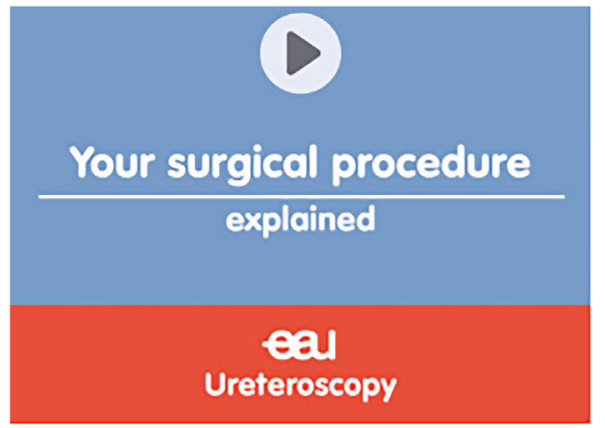

Fig. 1 - User interface graphic for the patient information video on ureteroscopy.

do not negatively influence high health literate audiences, “... information adapted to audiences with low health literacy suits people with high health literacy as well."

A 2016 study by Winter and colleagues [3] presented comparable results for patients undergoing insertion of a ureteric stent. The study looked at portable video media (PVM) versus standard verbal communication (SVC). The authors reported that 'PVM improves patients' understanding

A

Gender: Male / Female (please encircle)

Do you agree or disagree with the following statements on Ureteroscopy (URS)? (Please tick one box per statement. It is important that you provide an answer for every statement.)

\begin{tabular}{|c|c|c|c|c|c|}
\hline & $\begin{array}{c}\text { Strongly } \\
\text { agree }\end{array}$ & Agree & $\begin{array}{c}\text { Ido not } \\
\text { know }\end{array}$ & Disagree & $\begin{array}{l}\text { Strongly } \\
\text { Disagree }\end{array}$ \\
\hline 1. The URS video is easy to follow. & $\square$ & $\square$ & $\square$ & $\square$ & $\square$ \\
\hline $\begin{array}{l}\text { 2. The medical terms mentioned in the } \\
\text { video are easy to understand. }\end{array}$ & $\square$ & $\square$ & $\square$ & $\square$ & $\square$ \\
\hline $\begin{array}{l}\text { 3. I understand what a ureteroscope is } \\
\text { and how a stone is removed. }\end{array}$ & $\square$ & $\square$ & $\square$ & $\square$ & $\square$ \\
\hline $\begin{array}{l}\text { 4. I understand why I need to receive } \\
\text { anaesthesia. }\end{array}$ & $\square$ & $\square$ & $\square$ & $\square$ & $\square$ \\
\hline 5. I understand what a double J-stent is. & $\square$ & $\square$ & $\square$ & $\square$ & $\square$ \\
\hline $\begin{array}{l}\text { 6. I understand why I may have a } \\
\text { temporary double J-stent after the } \\
\text { URS. }\end{array}$ & $\square$ & $\square$ & $\square$ & $\square$ & $\square$ \\
\hline $\begin{array}{l}\text { 7. I understand that I may have to carry } \\
\text { a temporary urine catheter after the } \\
\text { URS. }\end{array}$ & $\square$ & $\square$ & $\square$ & $\square$ & $\square$ \\
\hline $\begin{array}{l}\text { 8. I understand why I need to undergo } \\
\text { the procedure. }\end{array}$ & $\square$ & $\square$ & $\square$ & $\square$ & $\square$ \\
\hline $\begin{array}{l}\text { 9. The video makes me feel more } \\
\text { confident about my procedure. }\end{array}$ & $\square$ & $\square$ & $\square$ & $\square$ & $\square$ \\
\hline $\begin{array}{l}\text { 10. The video has helped me prepare for } \\
\text { my procedure. }\end{array}$ & $\square$ & $\square$ & $\square$ & $\square$ & $\square$ \\
\hline $\begin{array}{l}\text { 11. The video has improved my } \\
\text { knowledge about the procedure. }\end{array}$ & $\square$ & $\square$ & $\square$ & $\square$ & $\square$ \\
\hline
\end{tabular}

With your help, we will be able to continue to improve the URS video. We would greatly appreciate it if you would answer the following questions. Please encircle one answer per question.

1. A double J-stent is used

b) to prevent or treat obstruction of the urine flow from the kidney due to swelling after the URS.

c) when URS is not possible.

2. In ureteroscopy, the access to the kidney is through:

a) the urethra.

b) an incision in the area of the kidney.

c) a small incision in the belly to introduce a camera and medical tools.

3. Which do you prefer?

a) Voice-over

c) Both voice-over and subtitles

4. In your opinion, is there something we have missed that should be included in the video? Please

let us know so that we may help viewers understand the procedure better. Feel free to use the back of this document if needed. compared with SVC and is a more effective means of content delivery to patients in terms of overall preference and knowledge gained during the consent process."

The EAU PI has already achieved success with its patient education materials (PEM), as found in a 2017 study by Betschart et al [4], who concluded that "the EAU provides carefully worked out PEM for 17 urological topics." The authors also mentioned that although they found improved readability compared to similar analyses, “ . . . a simplification of certain chapters might be helpful to facilitate better patient understanding."

Simplifying technical jargon and scientific data into a health message for the general public remains a challenge. The use of animated material and digital tools has undoubtedly opened another window of opportunity to provide a more patient-friendly format. Both the EAU Guidelines Office with its evidence-based recommendations and the European School of Urology with its comprehensive role in vital continuing medical education and training for urologists contributed significantly to the process.

There is no doubt that a better understanding of their health conditions by patients plays a crucial role in attitude and decision-making for treatment strategies. Today,

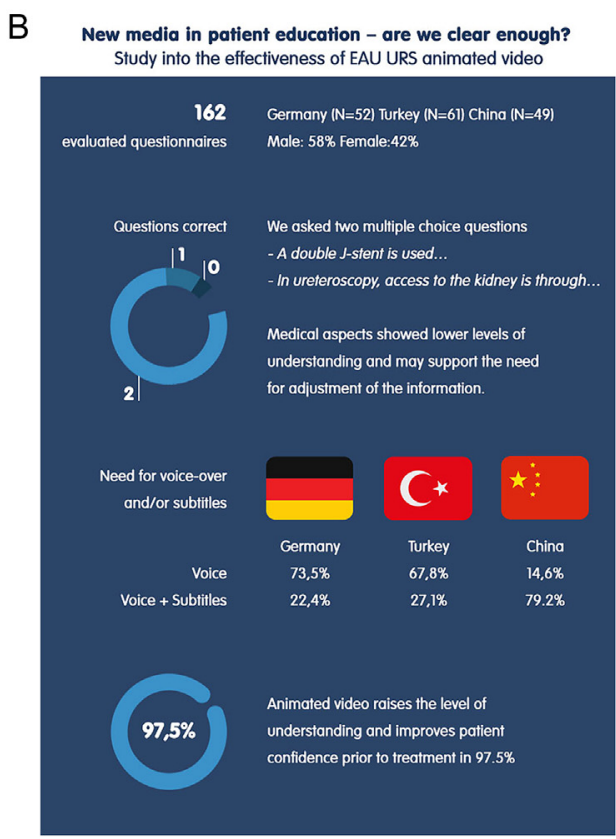

eas Patient Information

Fig. 2 - (A) The questionnaire used to evaluate patient understanding of ureteroscopy. (B) Summary of the results. 
opportunities are manifold, and it is important that the EAU exploits the benefits of these new digital tools to aid in collaborative decision-making. Undoubtedly, much work still needs to be done to improve the visibility, dissemination, and accessibility of the EAU PI, challenges that are now being addressed for the long term.

Conflicts of interest: The authors have nothing to disclose.

\section{References}

[1] Tanidir Y, Sarikaya S, Bach T, et al. New media in patient educationare we clear enough? A pilot study.Poster presentation at the 36th
World Congress of Endourology; September; 2018. https:// epostersonline.com/cie2018/node/148?.view=true

[2] Meppelink CS, van Weert J, Haven CJ, et al. The effectiveness of health animations in audiences with different health literacy levels: an experimental study. J Med Internet Res 2015;17:e11.

[3] Winter M, Kam J, Nalavenkata S, et al. The use of portable video media vs standard verbal communication in the urological consent process: a multicentre, randomised controlled, crossover trial. BJU Int 2016;118:823-8.

[4] Betschart P, Zumstein V, Bentivoglio M, et al. Readability assessment of online patient education materials provided by the European Association of Urology. Int Urol Nephrol 2017 2017;49:2111-7. http://dx.doi.org/10.1007/s11255-017-1695-7. 